\title{
Metastatic Tumor Site Indicator
}

National Cancer Institute

\section{Source}

National Cancer Institute. Metastatic Tumor Site Indicator. NCI Thesaurus. Code C154853.

An indication as to whether an anatomical location contains metastases. 